\title{
Primary Care Prognostic (PCP) Index of 11 -Year Mortality Risk: Development and Validation of a Brief Prognostic Tool
}

\author{
Grace Shu Hui Chiang, MMed, MPH'®, Ma Shwe Zin Nyunt, PhD'², Qi Gao, PhD ${ }^{3}$, \\ Shiou Liang Wee, PhD ${ }^{4}$, Keng Bee Yap, FRCS (Edinburgh) ${ }^{5}$, \\ Boon Yeow Tan, MMed, FCFP (Singapore) ${ }^{1,3}$, and Tze Pin Ng, MD ${ }^{4,6}$
}

\begin{abstract}
'Department of Medicine, St Luke's Hospital, Singapore, Singapore; ${ }^{2}$ Singapore Eye Research Institute, Singapore, Singapore; ${ }^{3}$ Yong Loo Lin School of Medicine, National University of Singapore, Singapore, Singapore; ${ }^{4}$ Geriatric Education and Research Institute, Singapore, Singapore; ${ }^{5}$ Department of Geriatric Medicine, Ng Teng Fong Hospital, Singapore, Singapore; ${ }^{6}$ Gerontology Research Programme, Department of Psychological Medicine, National University of Singapore, Singapore, Singapore.
\end{abstract}

BACKGROUND: Healthcare providers use a life expectancy of at least 5 to 10 years in shared clinical decision-making with older adults about cancer screening, major surgeries, and disease prevention interventions. At present, few prognostic indexes predict long-term mortality beyond 10 years or are suited for use in primary care settings.

OBJECTIVE: We developed and validated an 8-item multidimensional index predicting 11-year mortality for use in primary care.

DESIGN, SETTING, AND PARTICIPANTS: Using data from the Singapore Longitudinal Ageing Studies (SLAS), we developed a Primary Care Prognostic (PCP) Index for predicting 11-year mortality risk in a development cohort $(n=1550)$ and validated it in a geographically different cohort $(n=928)$.

MAIN MEASURES: The PCP Index was derived from eight indicators (body mass loss, weakness, slow gait, comorbidity, polypharmacy, IADL/BADL dependency, low albumin, low total cholesterol, out of 25 candidate indicators) using stepwise Cox proportional hazard models.

KEY RESULTS: In the developmental cohort, the mortality hazard ratio increased by 53\% per PCP point score increase, independent of age and sex. Across risk categories, absolute risks of mortality increased from 5\% (score 0) to $67.9 \%$ (scores 7-9), with area under curve (AUC = 0.77 (95\% CI 0.73-0.80)). The PCP Index also predicted mortality in the validation cohort, with AUC $=0.70$ (95\% CI 0.64-0.75).

CONCLUSIONS: The PCP Index using simple clinical assessments and point scoring is a potentially useful prognostic tool for predicting long-term mortality and is well suited for risk stratification and shared clinical decisionmaking with older adults in primary care.

KEY WORDS: older adults; prognosis; mortality; frailty; malnutrition.

J Gen Intern Med 36(1):62-8

DOI: $10.1007 / \mathrm{s} 11606-020-06132-2$

(c) Society of General Internal Medicine 2020

Electronic supplementary material The online version of this article (https://doi.org/10.1007/s11606-020-06132-2) contains supplementary material, which is available to authorized users.

Received May 7, 2020

Accepted August 11, 2020

Published online August 20, 2020

\section{INTRODUCTION}

In aging populations, escalating numbers of older adults in need of medical care present formidable healthcare challenges. ${ }^{1,2}$ Individualized management of older adults requires clinicians to consider patients' life expectancy in making shared clinical decisions regarding chronic disease management, major surgeries, and cancer screening. ${ }^{3}$ However, few prognostic indexes predict long-term mortality (beyond 10 years) in community-living older adults or can be easily used in primary care.

Current prognostic indexes face a number of issues that limit their application across a wide cross-section of patient groups and clinical settings. ${ }^{4-8}$ Tools developed from hospitalbased administrative data sets require information that are not routinely available or relevant in the primary care setting. Indexes based on multiple demographic, lifestyle, and behavioral risk, and disease variables are less relevant in older populations because predictors such as smoking, obesity, and chronic diseases are less important in the oldest old. ${ }^{9,} 10$ While the Multidimensional Prognostic Index (MPI) has shown good predictive accuracy for mortality risk, ${ }^{11}$ it requires a standard Comprehensive Geriatric Assessment (CGA) which is time-consuming and not practical in primary care settings.

Multidimensional tools which use items such as age, gender, instrumental activities of daily living, comorbidities, mood, cognitive function, and nutritional status have shown good predictive validity for 3 to 5 years, but have not been tested over longer time periods. ${ }^{8,12-16}$ Using data collected from community-dwelling older adults in the Singapore Longitudinal Ageing Studies (SLAS-1), we used a range of simple questionnaire, performance-based and blood indicators of health and functional status of older adults that are commonly used in primary care outpatient settings to develop a brief primary care prognostic index for predicting 11-year mortality risk in older adults. An 11-year mortality risk index was developed as few studies have evaluated long-term mortality risks of prognostic indices in population-based cohorts over periods longer than 5 or 10 years. This is important because 
current guidelines do not recommend some preventive interventions such as cancer screening when life expectancy is less than 10 years. ${ }^{17}$

\section{METHODS}

\section{Study Cohort}

Data was collected from an observational population-based cohort study of older adults, aged $\geq 55$ years in Singapore, with mortality follow-up from 1 September 2003 to 31 December 2014. Full details are previously described. ${ }^{18}$ Briefly, between 1 September 2003 and 31 December 2005, a whole area population of 2804 older adult residents in a dozen adjoining precincts in the South-East Region of Singapore were invited to participate in the study. Informed consent was obtained, and the study was approved by an institutional review board. At recruitment, questionnaires were administered using face-to-face interviews conducted by research nurses at the participants' homes. Clinical measurements and blood draws were performed at a local study site center.

\section{Development and Validation of the PCP Index}

The derivation of the PCP Index used a cohort of 1550 participants who were recruited from one defined geographical area during the period from 1 September to 31 December 2004. Our validation cohort ${ }^{19}$ was based on another cohort of 928 subjects who were recruited from a different residential area from 1 January 2005 to 31 December 2005.

A total of 25 performance-based and laboratory indicators of health and functional status of older adults were considered. (The full details for each measure are provided in Supplementary Table S1.) These indicators were selected for ease of collection in primary care settings and have been shown to predict mortality in older populations. ${ }^{20-45}$

\section{All-Cause Mortality Follow-up}

The follow-up vital status and date of death of the participants from baseline up to 31 December 2014 was determined by using the participants' unique National Registration Identity Card (NRIC) number matched to the National Death Registry. Two-hundred and forty-three participants died from 15,340 person-years of observation during a follow-up period of 11 years.

\section{Statistical analysis}

Cox regression models of time to event data, censored at the date of death or on 31 December 2014, and KaplanMeier plots of survival, with testing for proportional hazard assumptions and estimates of hazard ratios (HR) and $95 \%$ confidence intervals $(95 \% \mathrm{CI})$, were used to derive predictors of 11-year mortality. In the development cohort, we used a two-stage approach. We first identified variables that significantly predicted mortality in initial multivariable models in groups (NSI nutritional indicators, blood biomarkers, physical functional indicators, and other clinical and functional indicators) which also included age and sex. Variables significantly predicting mortality in each of the initial models were placed into a final stepwise multivariable model, along with age and sex. Forward stepwise elimination, backward stepwise elimination, and backward elimination were all tested, yielding the same results.

Using weights (rounded to the nearest integer) derived from regression coefficients, setting the lowest coefficient a score of 1 , a weighted summed score was derived to create the PCP Index. The summed scores across indicators range potentially from 0 to 10. The performance of the PCP Index's categorical levels: low $(0-1)$, medium $(2,3)$, high $(4,5)$, and very high $(6+)$ risk in predicting mortality risks were evaluated with HR estimates adjusted for age and sex. Discrimination of the model was assessed by receiver operating characteristic (ROC) curves and Harrel's C-statistics for mortality. We validated the PCP Index by comparing the predicted mortality from the development cohort to the observed mortality in the validation cohort. All analyses were performed using SAS 9.2 (SAS Institute, Inc., Cary, NC).

\section{RESULTS}

\section{Characteristics of Development Cohort Subjects}

The mean age of participants in the development cohort $(n=$ 1550) was 66.4 (SD 7.8). Sixty-two percent were women. Twenty-three percent had less than 6 years of formal education and were either single, divorced, or widowed. Forty percent had 3 or more comorbidities and $29 \%$ required assistance in either IADL or BADL (Table 1). During the 11 years of follow-up, $243(15.7 \%)$ participants died, from a total of 15,340 person-years of observation.

\section{Development Cohort}

Table 2 shows the mortality HR of association with the 25 individual indicators in separate models for clinical and functional indicators, physical functioning indicators, and nutritional indicators, controlling for age and sex. Four of the 11 NSI questionnaire indicators (inability to prepare meals or feed oneself, poor dentition, or oral issues causing difficulty eating, low intake of fruits or vegetables, take 3 more different drugs a day), and all blood, physical, clinical, and functional indicators, except low physical activity and depression, significantly predicted mortality independently of other indicators in their respective classes.

Table 3 shows the results when these significant indicators were entered simultaneously as candidate variables in the final 
Table 1 Baseline Characteristics of Participants in Development and Validation Cohorts

\begin{tabular}{|c|c|c|c|}
\hline & Development cohort & Validation cohort & $P$ value \\
\hline No. of subjects & 1550 & 928 & \\
\hline Female sex & $964(62.2)$ & $600(64.7)$ & $<0.001$ \\
\hline Age & $66.4 \pm 7.8$ & $65.4 \pm 7.1$ & $<0.001$ \\
\hline Less than 6 years of education & $364(23.5)$ & $103(11.1)$ & $<0.001$ \\
\hline Single, divorced or widowed & $366(23.6)$ & $263(28.3)$ & $<0.001$ \\
\hline Comorbidity $(\geq 3)$ & $629(40.6)$ & $427(46.0)$ & $<0.001$ \\
\hline Lived alone & $94(6.1)$ & $88(9.5)$ & $<0.001$ \\
\hline Body mass index, $\mathrm{kg} / \mathrm{m}^{2}$ & $23.5 \pm 3.6$ & $23.7 \pm 3.5$ & 0.28 \\
\hline Overweight or obese & $189(12.2)$ & $139(15.0)$ & 0.049 \\
\hline Albumin (g/L) & $41.8 \pm 3.4$ & $42.8 \pm 2.9$ & $<0.001$ \\
\hline Lymphocytes (per $\mathrm{mm}^{3}$ ) & $2034 \pm 599$ & $1900 \pm 542$ & $<0.001$ \\
\hline Total cholesterol (mmol/L) & $5.46 \pm 0.95$ & $5.45 \pm 0.97$ & 0.81 \\
\hline \multicolumn{4}{|l|}{ Food intake indicators } \\
\hline Physically unable to shop, cook and/or feed myself & $51(3.3)$ & $9(1.0)$ & $<0.001$ \\
\hline Take 3 or more different drugs a day & $366(23.6)$ & $251(27.1)$ & 0.056 \\
\hline Tooth or mouth problem causes difficulty eating & $105(6.8)$ & $23(2.5)$ & $<0.001$ \\
\hline Few fruit or vegetables (less than 2 portions per day) & $149(9.6)$ & $54(5.8)$ & 0.001 \\
\hline Illness/condition changes kind/amount of food eaten & 63941.2 & 36639.4 & 0.38 \\
\hline Fewer than 2 meals eaten per day & $46(3.0)$ & $11(1.2)$ & 0.004 \\
\hline Few milk products (less than once a day) & $1093(70.5)$ & $419(45.2)$ & $<0.001$ \\
\hline Alcohol 3 or more drinks almost every day & $57(3.7)$ & $24(2.6)$ & 0.14 \\
\hline Money not enough to buy needed food & $48(3.1)$ & $5(0.5)$ & $<0.001$ \\
\hline Eat alone most of the time & $234(15.1)$ & $127(13.7)$ & 0.34 \\
\hline Unintended loss/gain10lbs/4 kg last 6 months & $63(4.1)$ & $24(2.6)$ & 0.053 \\
\hline \multicolumn{4}{|l|}{ Blood nutritional indicators } \\
\hline Anemia $(<12$ Female, $<13$ Male $)$-WHO criteria & $236(15.2)$ & $103(11.1)$ & 0.004 \\
\hline Albumin L4 40g/L & $535(34.5)$ & $192(20.7)$ & $<0.001$ \\
\hline Low total cholesterol $<4.14 \mathrm{mmol} / \mathrm{L}$ & $116(7.5)$ & $75(8.1)$ & 0.59 \\
\hline Low lymphocyte count $<1200 / \mathrm{mm} 3$ & $79(5.1)$ & $68(7.3)$ & 0.023 \\
\hline \multicolumn{4}{|l|}{ Physical functional indicators } \\
\hline Weakness: unable to rise from chair (arms folded) & $352(22.7)$ & $134(14.4)$ & 0.000 \\
\hline Poor gait: POMA gait score $\leq 8$ & $67(4.3)$ & $12(1.3)$ & 0.000 \\
\hline Shrinking: BMI $<18.5$ or weight loss $^{1}$ & $151(9.7)$ & $67(7.2)$ & 0.032 \\
\hline Exhaustion & $168(10.8)$ & $46(5.0)$ & 0.000 \\
\hline Low physical activity ${ }^{2}$ & $339(21.9)$ & $311(33.5)$ & 0.000 \\
\hline Frail (Score: 3 to 5 ) & $67(4.3)$ & $16(1.7)$ & 0.000 \\
\hline \multicolumn{4}{|l|}{ Clinical indicators } \\
\hline Comorbidity ( 3 or more medical conditions) $)^{3}$ & $629(40.6)$ & $427(46.0)$ & 0.000 \\
\hline IADL or BADL disability $(\mathrm{Y} / \mathrm{N})^{4}$ & $449(29.0)$ & $155(16.7)$ & 0.000 \\
\hline Polypharmacy (6 or more drugs) & $170(11.0)$ & $94(10.1)$ & 0.51 \\
\hline Cognitive impairment (MMSE) & $234(15.1)$ & $55(5.9)$ & 0.000 \\
\hline Depression: GDS $\geq 10$ & $63(4.1)$ & $18(1.9)$ & 0.004 \\
\hline
\end{tabular}

${ }^{I}$ At least $5 \%$ of body weight or 10 pounds $(4.5 \mathrm{~kg})$ in the last 6 months or $3 \mathrm{~kg}(6.6$ pounds) in the last 3 months

${ }^{2}$ Self-report: "None" for participation in any moderate to heavy physical activity (walking or recreational or sports activity)

${ }^{3}$ Hypertension, lipid abnormality, diabetes, stroke, myocardial infarction, atrial fibrillation, heart failure, major eye disorder, end-stage renal failure, asthma, chronic obstructive lung disease, arthritis, hip fracture, mental illness, dementia, neurodegenerative diseases, cancer, other chronic diseases

${ }^{4}$ Unable to perform any of one or more IADL or BADL without assistance

model using backward and forward stepwise selection procedures. The final reduced model includes eight independent predictors of mortality, with HR ranging from 1.5 to 2.5. Two indicators are laboratory findings (low albumin and low total cholesterol), 5 are physical indicators (height loss, weakness, slow gait, functional disability), and 2 clinical indicators (multiple comorbidities and polypharmacy). The prognostic index scores ranged from 0 to 9 , mean (SD) of 2.1(2.0). There was a stepwise increase in mortality, from $5 \%$ for those with a score of 0 to $68 \%$ among those with a score of $7-9$, with distinct survival trajectories; these differences persisted over the 11 years of follow-up (Fig. 1). The area under the ROC (AUC) was 0.77 (95\% CI 0.73-0.80), compared with the corresponding area under the ROC for age, which was 0.73 $(0.70-0.77)$. An index combining the PCP Index with age did not significantly increase the AUC $(0.78,95 \%$ CI $0.74-0.80)$.

\section{Validation Cohort}

The mean age of participants in the validation cohort $(n=928)$ was 65 years, $64 \%$ were women. Eleven percent had less than 6 years of formal education and $28.3 \%$ were either single, divorced, or widowed. Forty-six percent had 3 or more comorbidities and $16.7 \%$ required assistance in either IADLs or BADLs (Table 1). During 9 years of follow-up, 86 participants died, from a total of 8342 person-years of observation.

The PCP Index scores in the validation cohort were lower than in the development cohort; the highest PCP Index score category (6-10) had no participants with scores greater than 6 . The mortality rates increased from 3.0 per 100 person-years among those with PCP Index score of 0 to 35.7 per 100 person-years among those with the highest PCP Index score of 6 (Table 4). The PCP Index showed good accuracy in discriminating between those who died and those who 
Table 2 Multivariable Models of Nutritional, Blood, and Clinical Indicators Predicting Mortality Risks in Development Cohort $(N=1550)$

\begin{tabular}{|c|c|c|c|c|}
\hline \multirow[t]{2}{*}{ Frailty indicators } & \multicolumn{4}{|c|}{ Multivariable Cox regression models } \\
\hline & $\boldsymbol{B}$ & SE & HR $(95 \%$ CI $)$ & $P$ value \\
\hline \multicolumn{5}{|l|}{ Model 1: Nutritional intake indicators } \\
\hline Unable to shop, cook and/or feed myself & 1.175 & 0.269 & $3.24(1.91-5.48)$ & $<0.0001$ \\
\hline Takes 3 or more different drugs a day & 0.542 & 0.141 & $1.72(1.30-2.27)$ & $<0.0001$ \\
\hline Difficulty eating & 0.511 & 0.204 & $1.67(1.12-2.49)$ & 0.012 \\
\hline Few fruit or vegetables: $<2$ portions per day & 0.461 & 0.188 & $1.58(1.10-2.29)$ & 0.014 \\
\hline Illness changes the kind/amount of food eaten & 0.028 & 0.137 & $1.03(0.79-1.35)$ & 0.836 \\
\hline Fewer than 2 meals eaten per day & 0.248 & 0.315 & $1.28(0.69-2.37)$ & 0.430 \\
\hline Few milk products (less than once a day) & 0.083 & 0.148 & $1.09(0.81-1.45)$ & 0.573 \\
\hline Alcohol 3 or more drinks almost every day & 0.104 & 0.316 & $1.11(0.60-2.06)$ & 0.742 \\
\hline Inadequate money to buy needed food & -0.070 & 0.322 & $0.93(0.50-1.75)$ & 0.828 \\
\hline Eats alone most of the time & 0.132 & 0.169 & $1.14(0.82-1.59)$ & 0.434 \\
\hline Unintended loss/gain $4 \mathrm{~kg}$ last 6 months & -0.075 & 0.316 & $0.93(0.50-1.72)$ & 0.811 \\
\hline \multicolumn{5}{|l|}{ Model 2: Laboratory indicators } \\
\hline Anemia: $<12$ female, $<13$ male - WHO criteria & 0.526 & 0.151 & $1.69(1.26-2.28)$ & 0.001 \\
\hline Albumin $<40 \mathrm{~g} / \mathrm{L}$ & 0.480 & 0.130 & $1.62(1.25-2.08)$ & $<0.001$ \\
\hline Low total cholesterol $<4.14 \mathrm{mmol} / \mathrm{L}$ & 0.938 & 0.173 & $2.55(1.82-3.59)$ & $<0.001$ \\
\hline Low lymphocyte count $<1200 / \mathrm{mm}^{3}$ & 0.633 & 0.217 & $1.88(1.23-2.88)$ & 0.004 \\
\hline \multicolumn{5}{|l|}{ Model 3: Physical functional indicators } \\
\hline Weakness: Chair rise (lowest 20\%) & 1.254 & 0.140 & $3.50(2.66-4.62)$ & 0.000 \\
\hline Poor gait: POMA gait score $\leq 8$ & 0.770 & 0.199 & $2.16(1.46-3.19)$ & 0.000 \\
\hline Low BMI $(<18.5)$ or weight loss ${ }^{1}$ & 0.481 & 0.180 & $1.62(1.14-2.30)$ & 0.008 \\
\hline Exhaustion & 0.394 & 0.169 & $1.48(1.06-2.07)$ & 0.020 \\
\hline Low physical activity ${ }^{2}$ & 0.109 & 0.146 & $1.11(0.84-1.48)$ & 0.455 \\
\hline \multicolumn{5}{|l|}{ Model 4: Clinical and other functional indicators } \\
\hline IADL or BADL disability $(\mathrm{Y} / \mathrm{N})^{3}$ & 1.018 & 0.134 & $2.77(2.13-3.60)$ & 0.000 \\
\hline Comorbidity ( 3 or more medical conditions $)^{4}$ & 0.510 & 0.146 & $1.66(1.25-2.22)$ & 0.000 \\
\hline Polypharmacy (6 or more drugs) & 0.509 & 0.169 & $1.66(1.19-2.32)$ & 0.003 \\
\hline Cognitive impairment & 0.523 & 0.137 & $1.69(1.29-2.21)$ & 0.000 \\
\hline Depression & 0.184 & 0.261 & $1.20(0.72-2.01)$ & 0.481 \\
\hline
\end{tabular}

Hazard ratio was controlled for age and sex included as covariates in the models

${ }^{1}$ At least $5 \%$ of body weight or 10 pounds $(4.5 \mathrm{~kg}$ ) in the last 6 months or $3 \mathrm{~kg}$ (6.6 pounds) in the last 3 months

${ }^{2}$ Self-report: "None" for participation in any moderate to heavy physical activity (walking or recreational or sports activity)

${ }^{3}$ Unable to perform any of one or more IADL or BADL without assistance

${ }^{4}$ Hypertension, lipid abnormality, diabetes, stroke, myocardial infarction, atrial fibrillation, heart failure, major eye disorder, end-stage renal failure, asthma, chronic obstructive lung disease, arthritis, hip fracture, mental illness, dementia, neurodegenerative diseases, cancer, other chronic diseases

survived, with C-statistic of 0.70 (Table 5). There was reasonably close agreement between the observed mortality in the development and validation cohorts for various levels of risk.

In addition, we tested a 6-item version of the PCP Index which did not require blood measures (potential range of scores 0 to 8 ) which has an AUC of 0.75 , with predicted probabilities of mortality ranging from $5.7 \%($ score $=0)$ to $78.3 \%$ (score $=7-8)$. (See Supplementary Table S2.)

\section{DISCUSSION}

We developed and validated a prognostic index using a simple point scoring method that can be used by primary care providers to stratify older adults on their risk of 11-year mortality. The index predicted 11-year mortality independently of age and sex, spanned a wide range of absolute mortality from 5 to $68 \%$, with uniformly wide

Table 3 Independent Risk Factors for 11-Year Mortality in the Development Cohort: Multivariable Cox Regression Final Selection Model $(N=$ 1238)

\begin{tabular}{|c|c|c|c|c|}
\hline PCP Index Indicators & $\boldsymbol{B}$ & SE & HR (95\% CI) & Points \\
\hline $\mathrm{BMI}<18.5$ or weight loss ${ }^{1}$ & 0.501 & 0.181 & $1.650(1.158-2.352)$ & 1 \\
\hline Weakness: unable to rise from chair (arms folded) & 0.922 & 0.148 & $2.515(1.880-3.363)$ & 2 \\
\hline Poor gait: POMA gait score $\leq 8$ & 0.505 & 0.201 & $1.657(1.119-2.455)$ & 1 \\
\hline Comorbidity ( 3 or more medical conditions $)^{2}$ & 0.375 & 0.151 & $1.456(1.083-1.956)$ & 1 \\
\hline Polypharmacy (6 or more drugs) ${ }^{3}$ & 0.378 & 0.171 & $1.460(1.044-2.041)$ & 1 \\
\hline IADL or BADL disability $(\mathrm{Y} / \mathrm{N})^{4}$ & 0.720 & 0.142 & $2.055(1.556-2.714)$ & 2 \\
\hline Low Albumin $(<40 \mathrm{~g} / \mathrm{L})$ & 0.533 & 0.130 & $1.704(1.320-2.199)$ & 1 \\
\hline Low total cholesterol $<4.14 \mathrm{mmol} / \mathrm{L}$ & 0.483 & 0.177 & $1.620(1.145-2.292)$ & 1 \\
\hline
\end{tabular}

${ }^{*}$ Hazard ratio was controlled for age and sex included as covariates in the models

${ }^{1}$ At least $5 \%$ of body weight or 10 pounds $(4.5 \mathrm{~kg}$ ) in the last 6 months or $3 \mathrm{~kg}$ (6.6 pounds) in the last 3 months

${ }^{2}$ Hypertension, lipid abnormality, diabetes, stroke, myocardial infarction, atrial fibrillation, heart failure, major eye disorder, end-stage renal failure, asthma, chronic obstructive lung disease, arthritis, hip fracture, mental illness, dementia, neurodegenerative diseases, cancer, other chronic diseases

${ }^{3}$ Oral medications, not including vitamins or supplements

${ }^{4}$ Unable to perform any of one or more IADL or BADL without assistance 


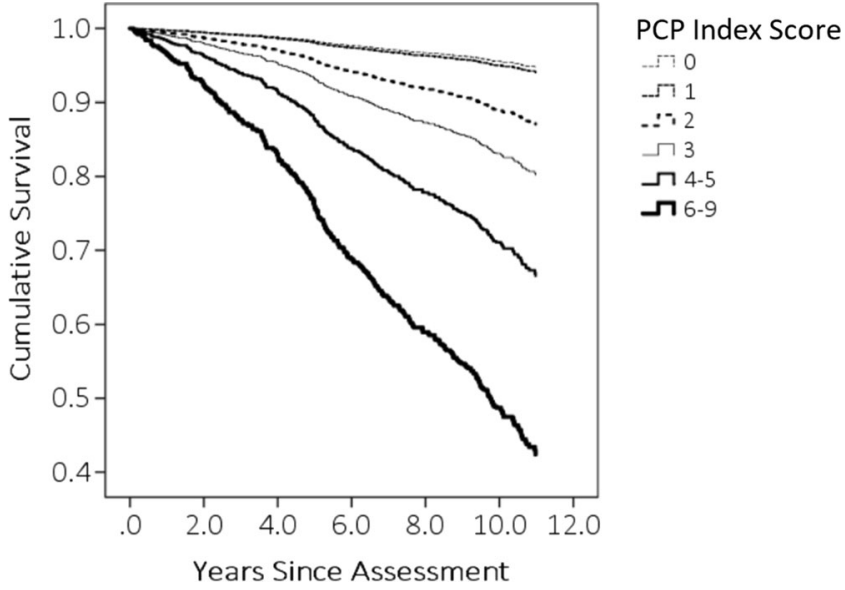

Figure 1 Kaplan-Meier survival of quartile risk groups over 11 years of follow-up.

separation across the different risk groups. The PCP Index predicted mortality in the validation cohort nearly as well as it did in the development cohort. The performance of the PCP Index compares favorably with that of other prognostic indexes that are also proposed for use by primary care providers for risk stratification of community-living older adults. ${ }^{13-16}$ Studies have reported that functional status adds modestly to mortality prediction in primary care beyond age, sex, and comorbidities. ${ }^{15,} 16$ Our study differs from previous studies by exploring a greater number of different and highprevalence functional indicators for predicting mortality in the model development. Our index differs by using physical and functional indicators of frailty and malnutrition and provides estimates of mortality over 11 years, longer than other studies.

Older patients with high mortality risk over 5 to 10 years may benefit from closer monitoring and targeted interventions to improve life expectancy and quality of life. This is because the PCP Index is distinctively based on measures of physical frailty and malnutrition and identifies older adults who are prefrail/frail and/or at-risk of malnutrition (or malnourished) with high mortality risks. These conditions have a high prevalence in older populations ${ }^{46,47}$ and should be monitored and treated. ${ }^{48}$ The PCP Index may thus be used in older patients for holistic management of malnutrition and frailty which may improve quality of life and survival. Additionally, the PCP Index may also be a useful tool in healthcare policy and epidemiological studies for risk adjustment in the evaluation of quality of care, medical effectiveness, and patient care outcomes among healthcare organizations.

Our study has several limitations. First, the validation cohort was younger, was better educated, had higher income, and was better housed than the development cohort and few had the highest PCP scores. Among the strata present, the PCP Index performed nearly as well as the development index. Secondly, the AUC for our index was only slightly higher than using age alone as the predictor of mortality. Interestingly, our index was independent of age and can be used as an additional clinical marker for providers in clinical decisionmaking. Third, the study was performed using only elderly Chinese residents. Whether it would perform as well in other countries and other ethnicities needs to be studied. Finally, the index was developed from community-living older adults; it may not be generalizable to populations in hospitals or nursing homes. Further studies should also be conducted to determine how the PCP Index compares with other prognostic indices and to determine its validity in populations with longer or shorter life expectancies.

Study strengths include using physical, nutritional, and functional indicators that are standard clinical measures that can be easily performed in primary care settings. The PCP Index measures take no longer than $10 \mathrm{~min}$ to complete.

Table 4 PCP Index Calibration: Mortality Rates According to Risk Score in the Development and Validation Cohorts

\begin{tabular}{|c|c|c|c|c|c|c|c|}
\hline \multirow[t]{2}{*}{ Score } & \multicolumn{4}{|c|}{ Development cohort } & \multicolumn{3}{|c|}{ Validation cohort } \\
\hline & Deaths & At risk & $\%$ & HR $^{*}(95 \% \mathrm{CI})$ & Deaths & At risk & $\%$ \\
\hline Per point & & & & $1.53(1.45-1.61)$ & & & \\
\hline \multicolumn{8}{|l|}{ Score } \\
\hline 0 & 19 & 382 & 5.0 & 1 (referent) & 9 & 297 & 3.0 \\
\hline 1 & 20 & 361 & 5.5 & $1.12(0.60-2.10)$ & 22 & 285 & 7.7 \\
\hline 2 & 31 & 257 & 12.1 & $2.54(1.43-4.50)$ & 13 & 123 & 10.6 \\
\hline 3 & 40 & 214 & 18.7 & $4.05(2.35-6.99)$ & 16 & 102 & 15.7 \\
\hline 4 & 41 & 127 & 32.3 & $7.62(4.42-13.1)$ & 7 & 54 & 13.0 \\
\hline 5 & 26 & 84 & 31.0 & $7.24(4.01-13.1)$ & 9 & 29 & 23.1 \\
\hline 6 & 28 & 69 & 40.6 & $11.2(6.23-20.0)$ & 10 & 28 & 35.7 \\
\hline $7+$ & 38 & 56 & 67.9 & $22.6(13.0-39.3)$ & & & \\
\hline C-statistic & & & $0.77(0.73-0.80)$ & $0.70(0.64-0.75)$ & & & \\
\hline \multicolumn{8}{|l|}{ Risk quartiles } \\
\hline $0-1$ & 39 & 743 & 5.2 & $1(-)$ & 31 & 582 & 5.3 \\
\hline $2-3$ & 71 & 471 & 15.1 & $2.49(1.68-3.69)$ & 29 & 225 & 12.9 \\
\hline $4-5$ & 67 & 211 & 31.8 & $4.23(2.79-6.43)$ & 16 & 82 & 20.7 \\
\hline $6-9$ & 66 & 125 & 52.8 & $7.34(4.73-11.4)$ & 10 & 28 & 35.7 \\
\hline C-statistic & & & $0.76(0.72-0.79)$ & $0.66(0.60-0.73)$ & & & \\
\hline
\end{tabular}

*Sex and age-adjusted 
Table 5 Primary Care Prognostic (PCP) Index

\begin{tabular}{|c|c|c|c|c|}
\hline \multicolumn{2}{|c|}{ Primary Care Prognostic (PCP) Index } & \multicolumn{3}{|c|}{$\begin{array}{l}\text { Circle scores } \\
\text { accordingly }\end{array}$} \\
\hline & Definition & No & Yes & Notes \\
\hline Low BMI & $\begin{array}{l}<18.5 \mathrm{~kg} / \mathrm{m}^{2} \text { or } \\
\text { weight loss }\end{array}$ & 0 & 1 & \\
\hline Weakness & $\begin{array}{l}\text { Unable to rise from a } \\
\text { chair (arms folded) }\end{array}$ & 0 & 2 & \\
\hline & POMA gait score $\leq 8$ & 0 & 1 & \\
\hline Comorbidities $^{2}$ & $\geq 3$ medical & 0 & 1 & \\
\hline Polypharmacy ${ }^{3}$ & $\geq 6$ drugs & 0 & 1 & \\
\hline Disability $^{4}$ & $\begin{array}{l}\text { Instrumental or basic } \\
\text { activity of daily } \\
\text { living }\end{array}$ & 0 & 2 & \\
\hline Low albumin & Albumin $<40 \mathrm{~g} / \mathrm{L}$ & 0 & 1 & \\
\hline Low total cholesterol & $\begin{array}{l}\text { Cholesterol }<4.14 \\
\mathrm{mmol} / \mathrm{L} \\
(<160 \mathrm{mg} / \mathrm{dL})\end{array}$ & 0 & 1 & \\
\hline \multicolumn{2}{|l|}{ Total Summed Score } & & 10 & $/ 10$ \\
\hline $\begin{array}{ll}\text { Scoring } & \begin{array}{l}\text { Mortality } \\
\text { risk }\end{array}\end{array}$ & $\begin{array}{l}\text { Estimated probability } \\
10 \text { years }\end{array}$ & & & \\
\hline Low & $5 \%$ & & & \\
\hline Medium & $15 \%$ & & & \\
\hline High & $32 \%$ & & & \\
\hline Very High & $55 \%$ & & & \\
\hline
\end{tabular}

${ }^{1}$ At least $5 \%$ of body weight or 10 pounds $(4.5 \mathrm{~kg})$ in the last 6 months or $3 \mathrm{~kg}$ (6.6 pounds) in the last 3 months

${ }^{2}$ Hypertension, lipid abnormality, diabetes, stroke, myocardial infarction, atrial fibrillation, heart failure, major eye disorder, end-stage renal failure, asthma, chronic obstructive lung disease, arthritis, hip fracture, mental illness, dementia, neurodegenerative diseases, cancer, other chronic diseases

${ }^{3}$ Oral medications, not including vitamins or supplements

${ }^{4}$ Unable to perform any one or more IADL or BADL without assistance

In addition, we developed and validated our measure in distinct patient populations. Third, our shorter prognostic indicator can be applied in the absence of having the serum markers available.

\section{CONCLUSION}

The Primary Care Prognostic Index using simple clinical assessments and point scoring is a prognostic tool for predicting long-term mortality risks that are well suited for risk stratification and shared clinical decision-making with older adults, as well as health policy formulation and research.

Acknowledgments: We thank the following voluntary welfare organizations for their support: Geylang East Home for the Aged, Presbyterian Community Services, St Luke's Eldercare Services, Thye Hua Kwan Moral Society (Moral Neighbourhood Links), Yuhua Neighbourhood Link, Henderson Senior Citizens' Home, NTUC Eldercare Co-op Ltd, Thong Kheng Seniors Activity Centre (Gueenstown Centre), and Redhill Moral Seniors Activity Centre.

Corresponding Author: Tze Pin Ng, MD; Gerontology Research Programme, Department of Psychological Medicine, National University of Singapore, Singapore, Singapore (e-mail: pcmngtp@nus.edu. sg).

Funding Information The study was supported by research grants from the Agency for Science Technology and Research (A*STAR) Biomedical Research Council (BMRC) [Grant: 08/1/21/19/567] and from the National Medical Research Council [Grant: NMRC/1108/2007].

\section{Compliance with Ethical Standards:}

Informed consent was obtained, and the study was approved by an institutional review board.

Conflict of Interest: The authors declare that they do not have a conflict of interest.

\section{REFERENCES}

1. Collard RM, Boter H, Schoevers RA, Voshaar RCO. Prevalence of frailty in community-dwelling older persons: a systematic review. J Am Geriatr Soc 2012;60(8): 1487-1492.

2. Fried LP, Ferrucci L, Darer J, Williamson JD, Anderson G. Untangling the concepts of disability, frailty, and comorbidity: implications for improved targeting and care. J Gerontol A Biol Sci Med Sci 2004;59(3):255-263.

3. Reilly BM, Magnussen CR, Ross J, Ash J, Papa L, Wagner M. Can we talk? Inpatient discussions about advance directives in a community hospital: attending physicians' attitudes, their inpatients' wishes, and reported experience. Arch Intern Med 1994;154(20):2299-2308.

4. Southern DA, Guan H, Ghali WA. Comparison of the Elixhauser and Charlson/Deyo methods of comorbidity measurement in administrative data. Med Care 2004;42(4):355-360.

5. Walter LC, Brand RJ, Counsell SR, et al. Development and validation of a prognostic index for 1-year mortality in older adults after hospitalization. Jama. 2001;285(23):2987-2994.

6. Inouye SK, Peduzzi PN, Robison JT, Hughes JS, Horwitz RI, Concato J. Importance of functional measures in predicting mortality among older hospitalized patients. Jama. 1998;279(15):1187-1193.

7. Carey EC, Walter LC, Lindquist $\mathbf{K}$, Covinsky KE. Development and validation of a functional morbidity index to predict mortality in community-dwelling elders. J Gen Intern Med 2004; 19(10):1027-1033.

8. Schonberg MA, Davis RB, McCarthy EP, Marcantonio ER. External validation of an index to predict up to 9-year mortality of communitydwelling adults aged 65 and older. J Am Geriatr Soc 2011;59(8):14441451.

9. Nybo H, Petersen HC, Gaist D, et al. Predictors of mortality in 2,249 nonagenarians-the Danish 1905-Cohort Survey. J Am Geriatr Soc 2003;51(10): 1365-1373.

10. Marengoni A, von Strauss E, Rizzuto D, Winblad B, Fratiglioni L. The impact of chronic multimorbidity and disability on functional decline and survival in elderly persons. A community-based, longitudinal study. $J$ Intern Med 2009;265(2):288-295.

11. Pilotto A, Ferrucci L, Franceschi M, et al. Development and validation of a multidimensional prognostic index for one-year mortality from comprehensive geriatric assessment in hospitalized older patients. Rejuvenation Res 2008;11(1):151-161.

12. Mazzaglia G, Roti L, Corsini G, et al. Screening of older communitydwelling people at risk for death and hospitalization: the Assistenza Socio-Sanitaria in Italia project. J Am Geriatr Soc 2007;55(12):19551960.

13. Jung HW, Kim JW, Han JW, et al. Multidimensional Geriatric Prognostic Index, Based on a Geriatric Assessment, for Long-Term Survival in Older Adults in Korea. PLoS One 2016;11(1):e0147032.

14. Angleman SB, Santoni G, Pilotto A, Fratiglioni L, Welmer AK. Multidimensional Prognostic Index in Association with Future Mortality and Number of Hospital Days in a Population-Based Sample of Older Adults: Results of the EU Funded MPI_AGE Project. PLoS One 2015;10(7):e0133789.

15. Carey IM, Shah SM, Harris T, DeWilde S, Cook DG. A new simple primary care morbidity score predicted mortality and better explains between practice variations than the Charlson index. J Clin Epidemiol 2013 Apr;66(4):436-44.

16. Sultana J, Fontana A, Giorgianni F, Basile G, Patorno E, Pilotto A, Molokhia M, Stewart R, Sturkenboom M, Trifirò G. Can information on functional and cognitive status improve short-term mortality risk prediction among community-dwelling older people? A cohort study using a UK primary care database. Clin Epidemiol 2017;10:31-39.

17. Bibbins-Domingo K, Grossman DC, Curry SJ, et al. Screening for colorectal cancer: US Preventive Services Task Force recommendation statement. Jama. 2016;315(23):2564-2575. 
18. Wei K, Nyunt MS, Gao Q, Wee SL, Yap KB, Ng TP. Association of Frailty and Malnutrition With Long-term Functional and Mortality Outcomes Among Community-Dwelling Older Adults: Results From the Singapore Longitudinal Aging Study 1. JAMA Netw Open 2018;1(3):e180650.

19. Justice AC, Covinsky KE, Berlin JA. Assessing the generalizability of prognostic information. Ann Intern Med 1999; 130(6):515-524.

20. Carey EC, Covinsky KE, Lui LY, Eng C, Sands LP, Walter LC. Prediction of mortality in community-living frail elderly people with long-term care needs. J Am Geriatr Soc 2008;56(1):68-75.

21. Fillenbaum GG, Pieper CF, Cohen HJ, Cornoni-Huntley JC, Guralnik JM. Comorbidity of five chronic health conditions in elderly community residents: determinants and impact on mortality. J Gerontol A Biol Sci Med Sci 2000;55(2):M84-89.

22. Ng TP, Niti M, Chiam PC, Kua EH. Prevalence and correlates of functional disability in multiethnic elderly Singaporeans. J Am Geriatr Soc 2006;54(1):21-29.

23. Ng TP, Niti M, Chiam PC, Kua EH. Physical and cognitive domains of the Instrumental Activities of Daily Living: validation in a multiethnic population of Asian older adults. J Gerontol A Biol Sci Med Sci 2006;61(7):726-735

24. Jyrkka J, Enlund H, Korhonen MJ, Sulkava R, Hartikainen S. Polypharmacy status as an indicator of mortality in an elderly population. Drugs Aging 2009;26(12): 1039-1048.

25. Sachs GA, Carter R, Holtz LR, et al. Cognitive impairment: an independent predictor of excess mortality: a cohort study. Ann Intern Med 2011;155(5):300-308.

26. Perna L, Wahl HW, Mons U, Saum KU, Holleczek B, Brenner $\mathbf{H}$. Cognitive impairment, all-cause and cause-specific mortality among nondemented older adults. Age Ageing 2015;44(3):445-451.

27. An R, Liu GG. Cognitive impairment and mortality among the oldest-old Chinese. Int J Geriatr Psychiatry 2016;31(12):1345-1353.

28. Ng TP, Niti M, Chiam PC, Kua EH. Ethnic and educational differences in cognitive test performance on mini-mental state examination in Asians. Am J Geriatr Psychiatry 2007;15(2): 130-139.

29. Cuijpers P, Schoevers RA. Increased mortality in depressive disorders: a review. Curr Psychiatry Rep 2004;6(6):430-437.

30. Nyunt MS, Fones C, Niti M, Ng TP. Criterion-based validity and reliability of the Geriatric Depression Screening Scale (GDS-15) in a large validation sample of community-living Asian older adults. Aging Ment Health 2009; 13(3):376-382.

31. Tinetti ME. Performance-oriented assessment of mobility problems in elderly patients. J Am Geriatr Soc 1986;34(2):119-126.

32. Harris T, Cook EF, Garrison R, Higgins M, Kannel W, Goldman L. Body mass index and mortality among nonsmoking older persons. The Framingham Heart Study. Jama. 1988;259(10):1520-1524.

33. Dey DK, Rothenberg E, Sundh V, Bosaeus I, Steen B. Body mass index, weight change and mortality in the elderly. A $15 \mathrm{y}$ longitudinal population study of 70 y olds. Eur J Clin Nutr 2001;55(6):482-492

34. Fried LP, Tangen $\mathbf{C M}$, Walston $\mathbf{J}$, et al. Frailty in older adults: evidence for a phenotype. J Gerontol A Biol Sci Med Sci 2001;56(3):M146-M157.
35. Wang $\mathbf{J Y}$, Tsai AC. The short-form mini-nutritional assessment is as effective as the full-mini nutritional assessment in predicting follow-up 4-year mortality in elderly Taiwanese. J Nutr Health Aging 2013;17(7):594-598.

36. Bouillanne O, Morineau G, Dupont C, et al. Geriatric Nutritional Risk Index: a new index for evaluating at-risk elderly medical patients. Am J Clin Nutr 2005;82(4):777-783.

37. Barrocas A, Bistrian BR, Blackburn GL, et al. Appropriate and effective use of the NSI checklist and screens. An update on caring for the elderly by preventing malnutrition. J Am Diet Assoc 1995;95(6):647-648.

38. de Groot LC, Beck AM, Schroll M, van Staveren WA. Evaluating the DETERMINE Your Nutritional Health Checklist and the Mini Nutritional Assessment as tools to identify nutritional problems in elderly Europeans. Eur J Clin Nutr 1998;52(12):877-883.

39. Schalk BW, Visser M, Deeg DJ, Bouter LM. Lower levels of serum albumin and total cholesterol and future decline in functional performance in older persons: the Longitudinal Aging Study Amsterdam. Age Ageing 2004;33(3):266-272.

40. Okamura T, Hayakawa T, Hozawa A, et al. Lower levels of serum albumin and total cholesterol associated with decline in activities of daily living and excess mortality in a 12-year cohort study of elderly Japanese. $J$ Am Geriatr Soc 2008;56(3):529-535.

41. Bae JM, Yang YJ, Li ZM, Ahn YO. Low cholesterol is associated with mortality from cardiovascular diseases: a dynamic cohort study in Korean adults. J Korean Med Sci 2012;27(1):58-63.

42. Dong X, Mendes de Leon C, Artz A, Tang Y, Shah R, Evans D. A population-based study of hemoglobin, race, and mortality in elderly persons. J Gerontol A Biol Sci Med Sci 2008;63(8):873-878.

43. Riva E, Tettamanti M, Mosconi P, et al. Association of mild anemia with hospitalization and mortality in the elderly: the Health and Anemia population-based study. Haematologica. 2009;94(1):22-28.

44. Chalmers KA, Knuiman MW, Divitini ML, Bruce DG, Olynyk JK, Milward EA. Long-term mortality risks associated with mild anaemia in older persons: the Busselton Health Study. Age Ageing 2012;41(6):759764.

45. Rubio-Rivas M, Formiga F, Grillo S, Gili F, Cabrera C, Corbella X. Lymphopenia as prognostic factor for mortality and hospital length of stay for elderly hospitalized patients. Aging Clin Exp Res 2016;28(4):721-727.

46. Verlaan S, Ligthart-Melis GC, Wijers SLJ, Cederholm T, Maier AB, de van der Schueren MAE. High Prevalence of Physical Frailty Among Community-Dwelling Malnourished Older Adults-A Systematic Review and Meta-Analysis. J Am Med Dir Assoc 2017; 18(5):374-382.

47. Wei K, Nyunt MSZ, Gao $\mathbf{Q}$, Wee SL, Ng TP. Frailty and Malnutrition: Related and Distinct Syndrome Prevalence and Association among Community-Dwelling Older Adults: Singapore Longitudinal Ageing Studies. J Am Med Dir Assoc 2017; 18(12): 1019-1028.

48. Dent E, Lien C, Lim WS, et al. The Asia-Pacific Clinical Practice Guidelines for the Management of Frailty. $J$ Am Med Dir Assoc $2017 ; 18(7): 564-575$

Publisher's Note: Springer Nature remains neutral with regard to jurisdictional claims in published maps and institutional affiliations. 